\title{
Mycobacterium tuberculosis Rv1096 protein: gene cloning, protein expression, and peptidoglycan deacetylase activity
}

\author{
Shufeng Yang ${ }^{1,2}$, Fei Zhang ${ }^{1}$, Jian Kang ${ }^{1}$, Wenli Zhang ${ }^{1}$, Guoying Deng ${ }^{1,2}$, Yi Xin $^{3}$ and Yufang Ma ${ }^{1,4^{*}}$
}

\begin{abstract}
Background: Many bacteria modulate and evade the immune defenses of their hosts through peptidoglycan (PG) deacetylation. The PG deacetylases from Streptococcus pneumonia, Listeria monocytogenes and Lactococcus lactis have been characterized. However, thus far, the PG deacetylase of Mycobacterium tuberculosis has not been identified.

Results: In this study, we cloned the Rv1096 gene from the M. tuberculosis H37Rv strain and expressed Rv1096 protein in both Escherichia coli and M. smegmatis. The results showed that the purified Rv1096 protein possessed metallo-dependent PG deacetylase activity, which increased in the presence of $\mathrm{Co}^{2+}$. The kinetic parameters of the PG deacetylase towards $M$. smegmatis PG as a substrate were as follows: $K_{m}, 0.910 \pm 0.007 \mathrm{mM} ; V_{\max }, 0.514 \pm 0.038 \mu \mathrm{Mmin}^{-1}$; and $K_{c a t}=0.099 \pm 0.007\left(S^{-1}\right)$. Additionally, the viability of $M$. smegmatis in the presence of over-expressed Rv1096 protein was $10^{9}$-fold higher than that of wild-type M. smegmatis after lysozyme treatment. Additionally, light microscopy and scanning electron microscopy showed that in the presence of over-expressed Rv1096 protein, M. smegmatis kept its regular shape, with an undamaged cell wall and smooth surface. These results indicate that Rv1096 caused deacetylation of cell wall PG, leading to lysozyme resistance in M. smegmatis.

Conclusion: We have determined that M. tuberculosis Rv1096 is a PG deacetylase. The PG deacetylase activity of Rv1096 contributed to lysozyme resistance in M. smegmatis. Our findings suggest that deacetylation of cell wall PG may be involved in evasion of host immune defenses by M. tuberculosis.
\end{abstract}

Keywords: Mycobacterium tuberculosis, Cell wall, Rv1096, Peptidoglycan deacetylase, Lysozyme

\section{Background}

Mycobacterium tuberculosis, the agent of tuberculosis, is associated with greater morbidity and longer dormancy infection times in humans than any other type of bacterial illness. Approximately one third of the population worldwide are infected with $M$. tuberculosis, which causes nearly two million deaths each year [1]. The chronic state and dormancy of tuberculosis implies that M. tuberculosis has developed sophisticated strategies to modify and evade the innate and adaptive immune surveillance mechanisms of humans [2].

\footnotetext{
*Correspondence: yufang_ma@hotmail.com

'Department of Biochemistry and Molecular Biology, Dalian Medical

University, 9 W Lushun South Road, Dalian 116044, China

${ }^{4}$ Liaoning Provincial Core Lab of Glycobiology and Glycoengineering, Dalian

116044, China

Full list of author information is available at the end of the article
}

M. tuberculosis has a distinctive cell wall structure, which is called the "core" mycolyl arabinogalactan-peptidoglycan (mAGP) complex. It is well-known that the bacterial cell wall is a reservoir for many essential biomolecules that interact with the surrounding environment. Peptidoglycan (PG) the skeletal structure of the cell wall, enables bacteria to resist osmotic pressure. The nucleotide-binding oligomerization domain (Nods) proteins in host cells, which have been identified as unique intracellular patternrecognition receptors of PG and PG-derived muropeptides, are potential virulence factors $[3,4]$. Therefore, bacteria may have developed PG modification properties to modulate Nods-mediated host surveillance [3]. This is evidenced from the role PG plays in the pathogenesis of Streptococcus pneumoniae [5], Listeria monocytogenes [6] and Helicobacter pylori [7]. 
Deacetylation of PG in several bacterial species, such as S. pneumonia, L. monocytogenes and Lactococcus lactis, prevents fusion of the phagosome with macrophage lysozyme [5,8-13]. Although peptidoglycan deacetylase has been identified in some bacteria [5-8], it has not yet been identified in M. tuberculosis.

M. smegmatis is commonly used as a model for studying gene function in $M$. tuberculosis because it proliferates rapidly and is non-pathogenic. $M$. smegmatis and $M$. tuberculosis have the same basic cell wall structure [14]. Therefore, $M$. smegmatis peptidoglycan can be used as a substrate to investigate peptidoglycan deacetylase activity.

In this study, we cloned M. tuberculosis Rv1096 and expressed Rv1096 protein in Escherichia coli and M. smegmatis. We determined the peptidoglycan deacetylase activity of purified Rv1096 and its biochemical characteristics. We also investigated whether the Rv1096 protein in M. smegmatis was lysozyme resistant.

\section{Methods}

\section{Bacterial strains and growth conditions}

E. coli NovaBlue (Novagen, Madison, WI) and ER2566 (Novagen) strains were routinely grown in Luria-Bertani media (LB, Invitrogen, Carlsbad, CA). The M. smegmatis $\mathrm{mc}^{2} 155$ (ATCC, USA) strain was grown in LB broth containing $0.05 \%(\mathrm{v} / \mathrm{v})$ Tween $80(\mathrm{LBT})$ or LB agar at $37^{\circ} \mathrm{C}$. Antibiotics were added at appropriate concentrations if needed. To prepare PG, M. smegmatis $\mathrm{mc}^{2} 155$ was grown in M9 minimal glucose medium (12.8 g sodium phosphate heptahydrate, $3 \mathrm{~g}$ potassium phosphate monobasic, $0.5 \mathrm{~g}$ sodium chloride, $1 \mathrm{~g}$ ammonium chloride, $0.24 \mathrm{~g}$ magnesium sulfate, $4 \mathrm{~g}$ glucose and $11.1 \mathrm{mg}$ calcium chloride per $\mathrm{L}$ ).

\section{Rv1096 cloning and expression vector construction} The Rv1096 was amplified from M. tuberculosis H37Rv genomic DNA (Colorado State University, USA) using Pfu DNA polymerase with Rv1096 primer 1 (5' TTCATATGCCGAAGCGACCCGACAAC 3'; the NdeI site is italics) and Rv1096 primer 2 (5' GGCAAGCTTTACG CACCGTTATTTGGC $3^{\prime}$; the HindIII site is italics). The $876 \mathrm{bp}$ PCR product was ligated to a PJET1.2 blunt vector to generate a pJET-Rv1096 plasmid, the presence of which was confirmed by DNA sequencing. Rv1096 was ligated to the NdeI and HindIII sites of pColdII (Takara, Dalian, China) to generate the pColdII-Rv1096 plasmid for expression in E. coli. Rv1096 was also ligated to the NdeI and HindIII sites of pVV2 (Colorado State University, USA) to obtain the pVV2-Rv1096 M. smegmatis expression plasmid (Table 1).

\section{Expression and purification of Rv1096 protein}

The pColdII-Rv1096 plasmid was transformed into E. coli ER2566 cells (Novagen) by a chemical transformation method [15]. E. coli ER2566 harboring the pColdII$R v 1096$ plasmid (ER2566/Rv1096, Table 1) was grown in $300 \mathrm{ml}$ of LB broth containing ampicillin $(100 \mu \mathrm{g} / \mathrm{ml})$ at $37^{\circ} \mathrm{C}$. Isopropyl-D-thiogalactopyranoside at a final concentration of $1 \mathrm{mM}$ was added to the culture when the $\mathrm{OD}_{600}$ reached 0.5 , after which the culture was incubated at $16^{\circ} \mathrm{C}$ for $24 \mathrm{~h}$.

The pVV2-Rv1096 plasmid was transformed into $M$. smegmatis $\mathrm{mc}^{2} 155$ using an electroporation method [15]. M. smegmatis $\mathrm{mc}^{2} 155$ harboring the $\mathrm{pVV} 2-R v 1096$ plasmid (M. smegmatis/Rv1096, Table 1) was grown in $300 \mathrm{ml}$ of LBT broth with kanamycin at $50 \mu \mathrm{g} / \mathrm{ml}$ at $37^{\circ} \mathrm{C}$ for $24 \mathrm{~h}$.

The cultures were centrifuged at $5000 \times \mathrm{g}$ for $15 \mathrm{~min}$ and the cell pellets were resuspended in $5 \mathrm{ml}$ of lysis buffer $(500 \mathrm{mM}$ Tris- $\mathrm{HCl}, \mathrm{pH} 8.0,20 \mathrm{mM} \mathrm{NaCl}$ and $20 \%$ glycerol) with $1 \mathrm{mM}$ phenylmethyl sulfonyl fluoride. After sonication, the lysates were centrifuged at $15000 \times$ $\mathrm{g}$ for $20 \mathrm{~min}$ and the supernatant fraction was loaded onto a Ni-NTA column (Qiagen, Hilden, Germany) by gravity flow. The column was washed with $20 \mathrm{ml}$ of wash buffer $(20 \mathrm{mM}$ Tris- $\mathrm{HCl}, \mathrm{pH} 8.0,500 \mathrm{mM} \mathrm{NaCl}$, $20 \%$ glycerol and $30 \mathrm{mM}$ imidazole). The purified protein was eluted with $10 \mathrm{ml}$ of elution buffer $(20 \mathrm{mM}$

Table 1 Bacteria and plasmids

\begin{tabular}{|c|c|c|}
\hline Bacteria and plasmids & Relevant characteristic(s) & Resource \\
\hline \multicolumn{3}{|l|}{ Strains } \\
\hline E. coli NovaBlue & Used for cloning and propagation of plasmids & Novagen \\
\hline E. coli ER2566 & Used for expression of Rv1096 protein & Novagen \\
\hline M. smegmatis & $\mathrm{mc}^{2} 155$ strain, used for expression of Rv1096 protein and preparation of peptidoglycan & ATCC \\
\hline E. coli ER2566/Rv1096 & E. coli ER2566 carrying pColdll-Rv1096 plasmid & This work \\
\hline M. smegmatis/Rv1096 & M. smegmatis mc ${ }^{2} 155$ carrying pW2-Rv1096 plasmid & This work \\
\hline \multicolumn{3}{|l|}{ Plasmids } \\
\hline pJET1.2/blunt vector & Carries $a m p^{R}$ gene; used for cloning PCR product & Fermentas \\
\hline pColdll-Rv1096 & Carries $a m p^{R}$ gene; used for expression Rv1096 protein in E. coli ER2566 & This work \\
\hline pW2-Rv1096 & Carries kan $^{R}$ gene; used for expression of Rv1096 protein in M. smegmatis $\mathrm{mc}^{2} 155$ & This work \\
\hline
\end{tabular}


Tris- $\mathrm{HCl}, \mathrm{pH}$ 8.0, $500 \mathrm{mM} \mathrm{NaCl}$ and $200 \mathrm{mM}$ imidazole), and the first $3 \mathrm{ml}$ was collected for sodium dodecyl sulfate polyacrylamide gel electrophoresis (SDS-PAGE) and western blotting, as well as deacetylase activity detection. The purified protein $(1.25 \mu \mathrm{g})$ was subjected to $12 \%$ SDS-PAGE and then transferred to a nitrocellulose membrane (PALL, NY, USA) in blotting buffer (20 mM Tris-base, $150 \mathrm{mM}$ glycine and 20\% methanol, $\mathrm{pH}$ 8.3). After blocking with $10 \%$ non-fat dry milk in TBST buffer $(10 \mathrm{mM}$ Tris- $\mathrm{HCl}$, $\mathrm{pH}$ 8.0, $150 \mathrm{mM} \mathrm{NaCl}$ and $0.05 \%$ Tween 20), the membrane was incubated with a monoclonal (anti)-polyhistidine His-1 antibody (1:5000; Sigma-Aldrich). The membrane was washed with TBST buffer three times and then incubated with alkaline-phosphatase conjugated anti-mouseIgG (1:2500, Sigma-Aldrich). The His ${ }_{6}$-tagged-protein band was visualized with 5-bromo-4-chloro-3-indolyl phosphate and nitro blue tetrazolium (Sigma-Aldrich) solution.

\section{Preparation of $M$. smegmatis PG}

M. smegmatis PG was prepared from cell wall fractions as described previously [16-18]. Briefly, a $500 \mathrm{ml}$ culture of M. smegmatis $\mathrm{mc}^{2} 155$ in M9 minimal glucose medium was harvested when the $\mathrm{OD}_{600}$ reached 0.6, after which the cells were washed three times with pre-cooled phosphate buffered saline (PBS: $137 \mathrm{mM} \mathrm{NaCl}, 2.7 \mathrm{mM} \mathrm{KCl}$, $10 \mathrm{mM} \mathrm{Na}{ }_{2} \mathrm{HPO}_{4}, 2 \mathrm{mM} \mathrm{KH} \mathrm{PO}_{4}, \mathrm{pH} \mathrm{7.0)}$. The pellets were resuspended in distilled water to $0.2 \mathrm{~g} / \mathrm{ml}$, mixed with an equal volume of boiling $8 \%$ SDS added drop-wise with continuous boiling for $30 \mathrm{~min}$. A cell-wall-enriched fraction was obtained by centrifugation at $100,000 \times \mathrm{g}$ at $20^{\circ} \mathrm{C}$ for $60 \mathrm{~min}$, followed by three washes with pre-cooled PBS. The pellet was washed with distilled water at least six times to remove the SDS. The sample was resuspended in $5 \mathrm{ml}$ of buffer $(10 \mathrm{mM}$ Tris- $\mathrm{HCl}$ and $10 \mathrm{mM} \mathrm{NaCl}$, $\mathrm{pH}$ 7.0) and then sonicated for 5 min. $\alpha$-amylase and imidazole were added to the sample at final concentrations of $100 \mu \mathrm{g} / \mathrm{ml}$ and $0.32 \mathrm{M}$, respectively, and the solution was incubated at $37^{\circ} \mathrm{C}$ for $2 \mathrm{~h}$ to remove glycogen. Afterwards, proteinase $\mathrm{K}$ was added to the sample at a final concentration of $100 \mu \mathrm{g} / \mathrm{ml}$, followed by incubation at $37^{\circ} \mathrm{C}$ for $1.5 \mathrm{~h}$ to remove lipoprotein. The proteinase $\mathrm{K}$ solution was then inactivated by addition of an equal volume of boiling $8 \%$ SDS with vigorous stirring for $15 \mathrm{~min}$. The mixture was ultracentrifuged at $100,000 \times \mathrm{g}$ at $20^{\circ} \mathrm{C}$ for $30 \mathrm{~min}$. The pelleted material was washed as described above. The resulting mAGP (mycolyl-arabinogalactan-peptidoglycan) complex was washed with acetone and dried under a vacuum. Mycolic acids were removed with $1 \%$ potassium hydroxide in methanol at $37^{\circ} \mathrm{C}$ for $72 \mathrm{~h}$. After room temperature centrifugation at $27,000 \times \mathrm{g}$ for $30 \mathrm{~min}$, the pelleted arabinogalactan-PG was washed with distilled water twice and dried under a vacuum. Arabinogalactan was removed by washing with $49 \%$ hydrofluoridic acid at $4^{\circ} \mathrm{C}$ for $120 \mathrm{~h}$ with stirring. The resulting PG was pelleted by room temperature centrifugation at $27,000 \times \mathrm{g}$ for $30 \mathrm{~min}$ and then washed as described above. The PG was dissolved in $50 \mathrm{mM}$ HEPS buffer $(\mathrm{pH} 7.0)$ at $1 \mathrm{mg} / \mathrm{ml}$ until further use.

\section{Deacetylase activity assays}

The acetyl group released from the PG was measured using an acetic acid detection kit (Roche, Darmstadt, Germany). Briefly, Rv1096 protein $(2.88 \mu \mathrm{g} / \mathrm{ml})$ prepared from ER2566/Rv1096 and M. smegmatis/Rv1096 were separately incubated with $M$. smegmatis PG. The reactions were performed at $37^{\circ} \mathrm{C}$ for $30 \mathrm{~min}$ and stopped by 10 min boiling. After room temperature centrifugation at $5000 \times \mathrm{g}$ for $10 \mathrm{~min}$, the supernatant was collected for acetic acid measurement using a spectrophotometric assay accordingly to the kit instructions.

The kinetic properties of the Rv1096 protein toward M. smegmatis PG were determined as described previously [19]. The molarity of M. smegmatis PG was calculated based the assumption that M. smegmatis PG is primarily composed of repeat units of GlcNAc-MurNAc (MurNGlyc)-L-Ala-D-Glu-A 2 pm, MW 868.8 [20-22]. First, the initial velocity was evaluated according to the duration of each reaction $(5,10,15,30$ or $45 \mathrm{~min})$ and the Rv1096 concentration $(1.22,2.88$ or $3.65 \mu \mathrm{g} / \mathrm{ml})$ curves. Then, the optimal conditions for the enzymatic reactions were determined. Based on the initial velocity and the optimal conditions that we identified, the steady-state kinetic parameters were determined by a Lineweaver-Burke plot.

\section{Lysozyme susceptibility assays}

To investigate whether the Rv10196 protein contributed to lysozyme resistance in $M$. smegmatis, wild-type $M$. smegmatis or M. smegmatis/Rv1096 with over-expressed Rv1096 protein were treated with lysozyme. Both bacterial strains were incubated in LBT medium at $37^{\circ} \mathrm{C}$. When the $\mathrm{OD}_{600}$ reached $\sim 0.2$, the cultures were divided into two equal volumes parts. One part was treated with lysozyme (SigmaAldrich) at a final concentration of $200 \mu \mathrm{g} / \mathrm{ml}$; the other was not given this treatment. Bacterial growth was monitored by measuring the optical density at $600 \mathrm{~nm}$. Bacterial viability was evaluated by counting the number of colony forming units (CFU) per milliliter on LB agar [23].

\section{Morphology of the M. smegmatis strains after lysozyme treatment}

Light microscopy and electron microscopy were used to investigate whether the Rv1096 protein affected the morphology of M. smegmatis in the presence of lysozyme. Bacteria that were treated with lysozyme for $9 \mathrm{~h}$ were harvested by centrifugation at $4,500 \times \mathrm{g}$ at $4^{\circ} \mathrm{C}$ for $10 \mathrm{~min}$, after which the pellets were washed with sterilized 1 M PBS ( $\mathrm{pH} 7.0$ ), three times. Samples were prepared for Ziehl-Neelsen acid-fast staining as described previously [24], and observed under a light microscope 
(Olympus CHB, Japan). The cells for electron microscopic analysis were fixed with $2.5 \%$ glutaraldehyde, followed by post-fixation at room temperature for $2 \mathrm{~h}$ with $1 \%$ osmium tetroxide. The samples were dehydrated with ethanol, which was replaced with liquid carbon dioxide by critical point drying. The dried samples were applied to a silicon wafer slide and sputter-coated with gold before examination by an electronic microscope (JSM-6360 scanning electron, JEOL, Japan).

\section{Statistical analysis}

Data are summarized as mean value \pm standard deviation (SD). Data were assessed by two-tailed unpaired $t$ tests. A $p$ value of $<0.05$ was considered statistically significant.

\section{Results}

Rv1096 shares homology with other deacetylases

The amino acid sequences of the Rv1096 protein and other known polysaccharide deacetylases [5,8-12] were compared by Multalin analysis. The S. pneumoniae PgdA protein (spPdgA), L. monocytogenes PgdA (lmo0415) and $L$. lactis PgdA (XynD) were identified as $\mathrm{N}$-acetylglucosamine deacetylase proteins containing CE-4 NodB domains $[10,25,26]$. Rv1096 also contained a CE-4 NodB domain. Rv1096 shared 31.6\% sequence identity with the S. pneumoniae PgdA protein, whose deacetylase domain has recently been defined as a crystal structure $[10,25]$. The catalytic core of the amino acids involved in deacetylase activity is highly conserved between Rv1096 and S. pneumoniae PgdA proteins (Figure 1).

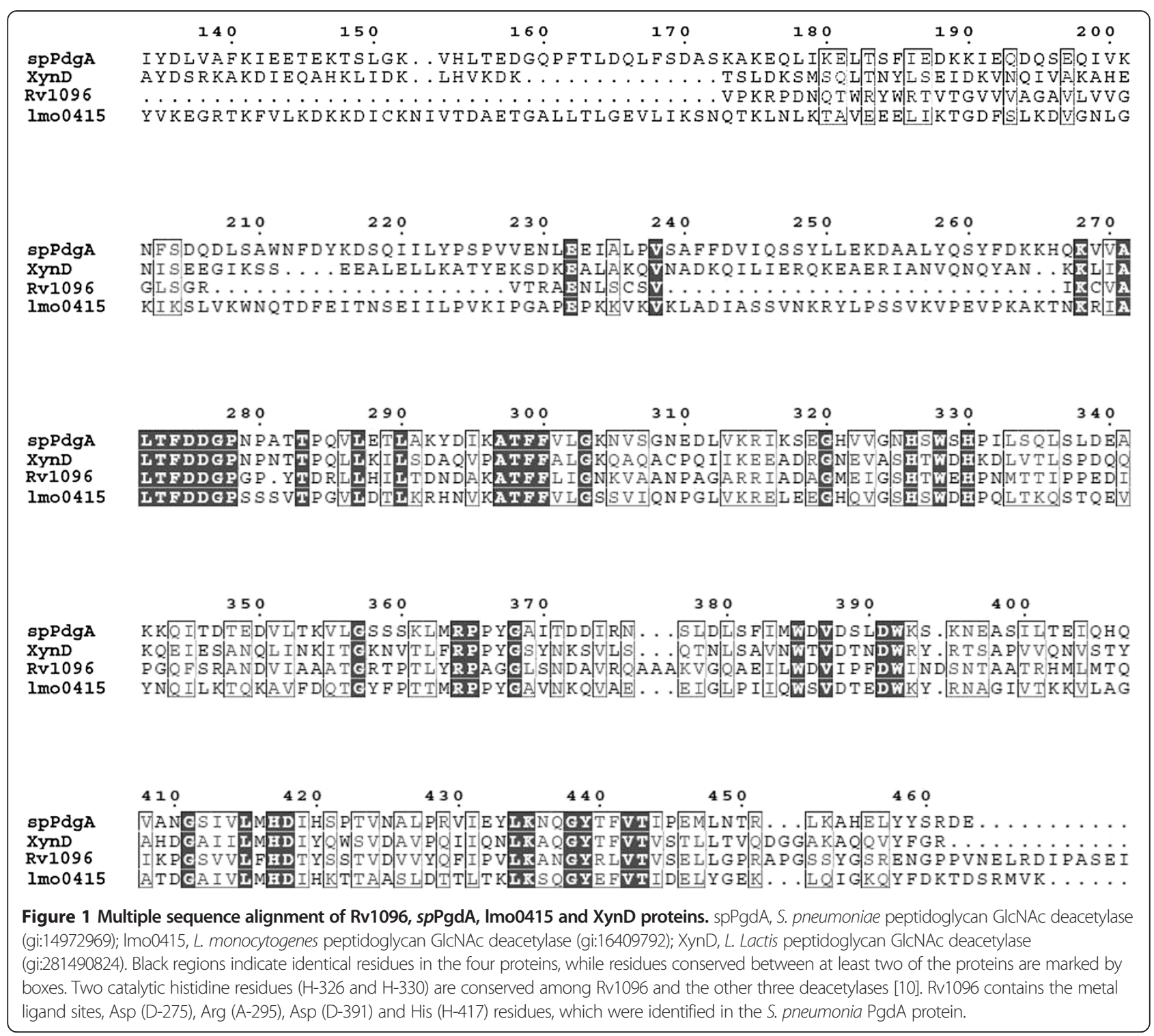




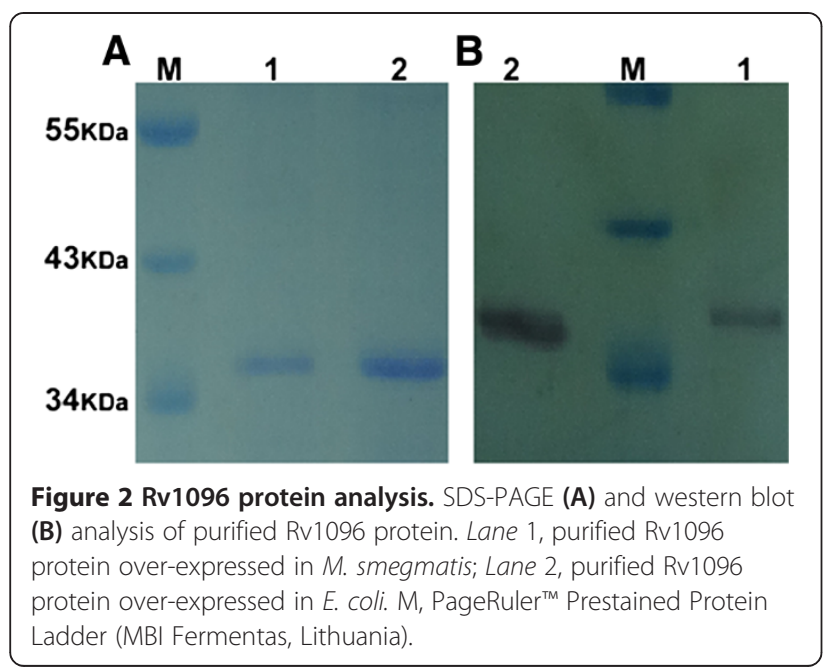

Rv1096 overexpressed in E. coli and M. smegmatis is a soluble protein

Soluble Rv1096 protein, over-expressed in both E. coli and M. smegmatis, was purified by Ni-NTA affinity chromatography. The purified Rv196 protein was analyzed by SDSPAGE and western blotting (Figure 2). The results showed that purified Rv1096 had a molecular weight of $35 \mathrm{kDa}$.

\section{Rv1096 exhibits peptidoglycan deacetylase activity}

To assess its deacetylase activity, Rv1096 protein at 1.22, $2.88,3.65$ or $4.74 \mu \mathrm{g} / \mathrm{ml}$ was incubated with $M$. smegmatis PG at $1 \mathrm{mg} / \mathrm{ml}$. The acetyl group released from PG was measured using an acetic acid detection kit (Roche Diagnostics, Germany). The results revealed that the purified Rv1096 protein over-expressed in both E. coli and $M$. smegmatis exhibited peptidoglycan deacetylase activity (Figure 3A). There was no significant difference between the Rv1096 proteins prepared from either bacterium in terms of their specific enzymatic activities ( $p>0.05)$. Therefore, the Rv1096 protein prepared from E. coli was used for the following enzyme kinetics experiments as it was easier to prepare and produced a greater yield than that produced in $M$. smegmatis.

According to the time versus concentration curve (Figure 3B), when the Rv1096 protein concentration was $2.88 \mu \mathrm{g} / \mathrm{ml}$, acetic acid was released at a constant rate over a $30 \mathrm{~min}$ period. Therefore, the initial velocity range fell within $30 \mathrm{~min}$, and the optimal concentration for Rv1096 was $2.88 \mu \mathrm{g} / \mathrm{ml}$. The optimal deacetylation reaction conditions were determined by changing the $\mathrm{pH}$ and temperature of the reaction. From this, the optimal $\mathrm{pH}$ was found to be 7.0 and the optimal temperature $37^{\circ} \mathrm{C}$ (data not shown). The kinetic parameters were calculated by a

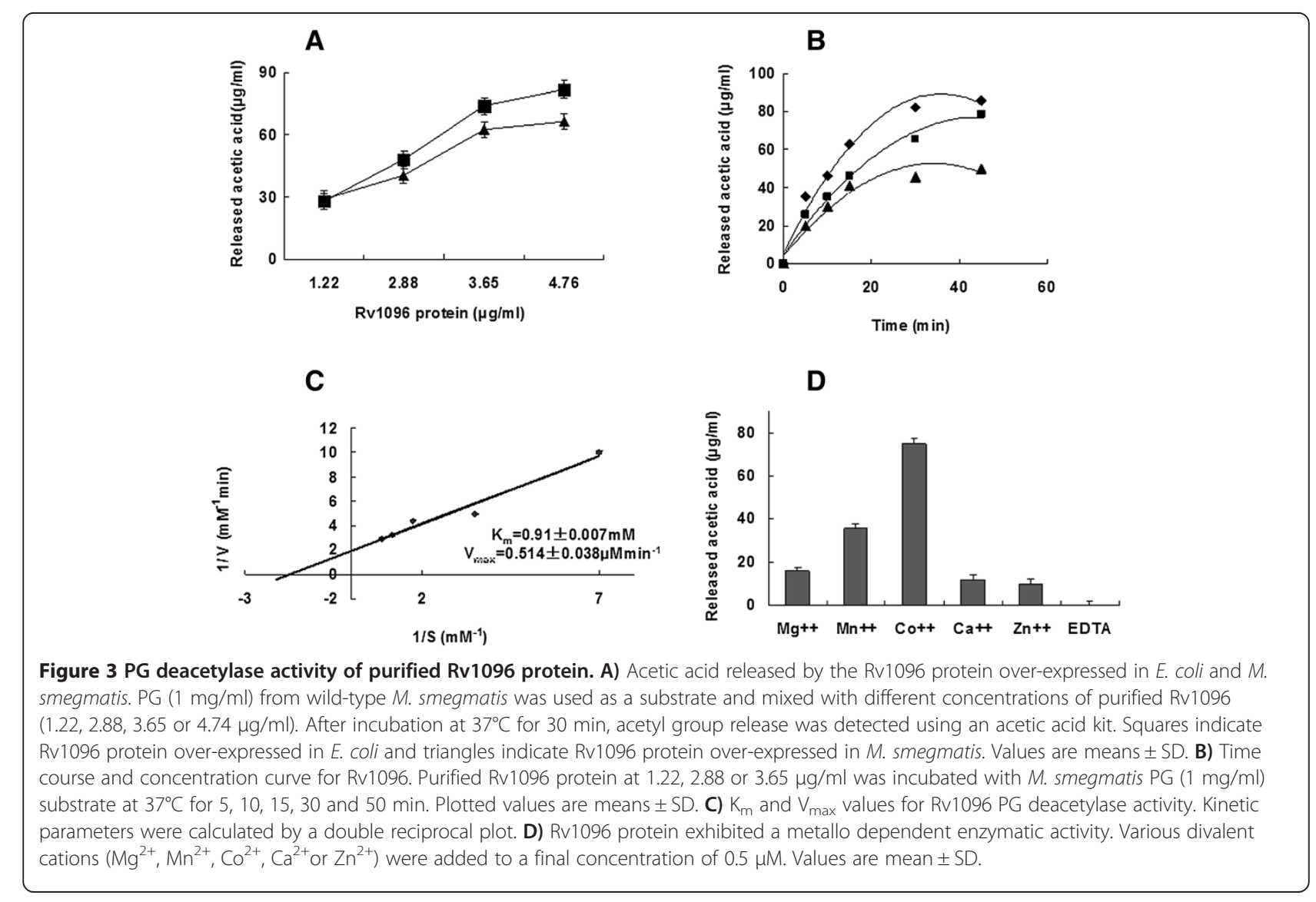


double reciprocal plot (Figure 3C): $\mathrm{K}_{\mathrm{m}}=0.910 \pm 0.007 \mathrm{mM}$; $\mathrm{V}_{\max }=0.514 \pm 0.038 \mu \mathrm{M} \min ^{-1}$; and $\mathrm{K}_{\text {cat }}=0.099 \pm 0.007$ $\left(\mathrm{S}^{-1}\right)$.

As shown in Figure 1, Rv1096 contained the same AspHis-His conserved residues known to interact with $\mathrm{Co}^{2+}$ in S. pneumoniae PgdA. To ensure that Rv1096 was also a metallo-dependent deacetylase, various divalent cations $\left(\mathrm{Mg}^{2+}, \mathrm{Mn}^{2+}, \mathrm{Co}^{2+}, \mathrm{Ca}^{2+}\right.$ or $\left.\mathrm{Zn}^{2+}\right)$ were added to the reaction buffer, each at a final concentration of $0.5 \mu \mathrm{M}$; EDTA at $50 \mu \mathrm{M}$ served as a control. The results showed that the enzymatic reactivity reached the highest level in the presence of $\mathrm{Co}^{2+}$; however, enzymatic activity was lost in the presence of EDTA (Figure 3D). Therefore, we determined that Rv1096 is a metallo-dependent PG deacetylase.

\section{M. smegmatis/Rv1096 exhibits lysozyme resistance}

To determine the contribution of Rv10196 protein to $M$. smegmatis resistance to lysozyme, M. smegmatis/Rv1096 and wild-type $M$. smegmatis cultures were divided into two parts at the beginning of the exponential growth phase. Test samples received $200 \mu \mathrm{g} / \mathrm{ml}$ lysozyme, unlike the control samples. As shown in Figure 4A, the wild-type M. smegmatis culture suspension treated with lysozyme lost its opaque, hazy appearance, becoming transparent at the end of the exponential growth phase, or shortly after reaching stationery phase. Its $\mathrm{OD}_{600}$ and CFU values decreased, indicating that cell lysis took place in the wildtype lysozyme-treated $M$. smegmatis. The M. smegmatis/ Rv1096 growth curves for lysozyme treatment showed almost no difference to the lysozyme-untreated group, suggesting that Rv10196 protein contributed to M. smegmatis resistance to lysozyme degradation. There was also no significant difference between the M. smegmatis/Rv1096 and wild-type $M$. smegmatis treated with lysozyme in terms of bacterial viability within the initial four hours of growth (Figure 4B). However, viable wild-type M. smegmatis bacteria decreased rapidly after lysozyme treatment for $4 \mathrm{~h}$. A significant difference $(\mathrm{P}<0.01)$ in viability was observed between $M$. smegmatis/Rv1096 and wild-type M. smegmatis after lysozyme treatment for $9 \mathrm{~h}$. About $10^{7}$ wild-type M. smegmatis cells survived, whereas only $10^{16} \mathrm{M}$. smegmatis/Rv1096 cells survived.

The M. smegmatis/Rv1096 cell wall was undamaged by $9 \mathrm{~h}$ of lysozyme treatment

Because the most apparent differences in bacterial growth and viability were observed (Figures $4 \mathrm{~A}$ and $\mathrm{B}$ ) after treatment with lysozyme for $9 \mathrm{~h}$, morphological observations were performed at this time point. The results of the ZiehlNeelsen acid-fast staining showed that wild-type $M$. smegmatis lost its acid-fastness and became blue dyed, whereas M. smegmatis/Rv1096 retained its acid-fastness (Figure 5). Scanning electronic microscopy (SEM) showed that the

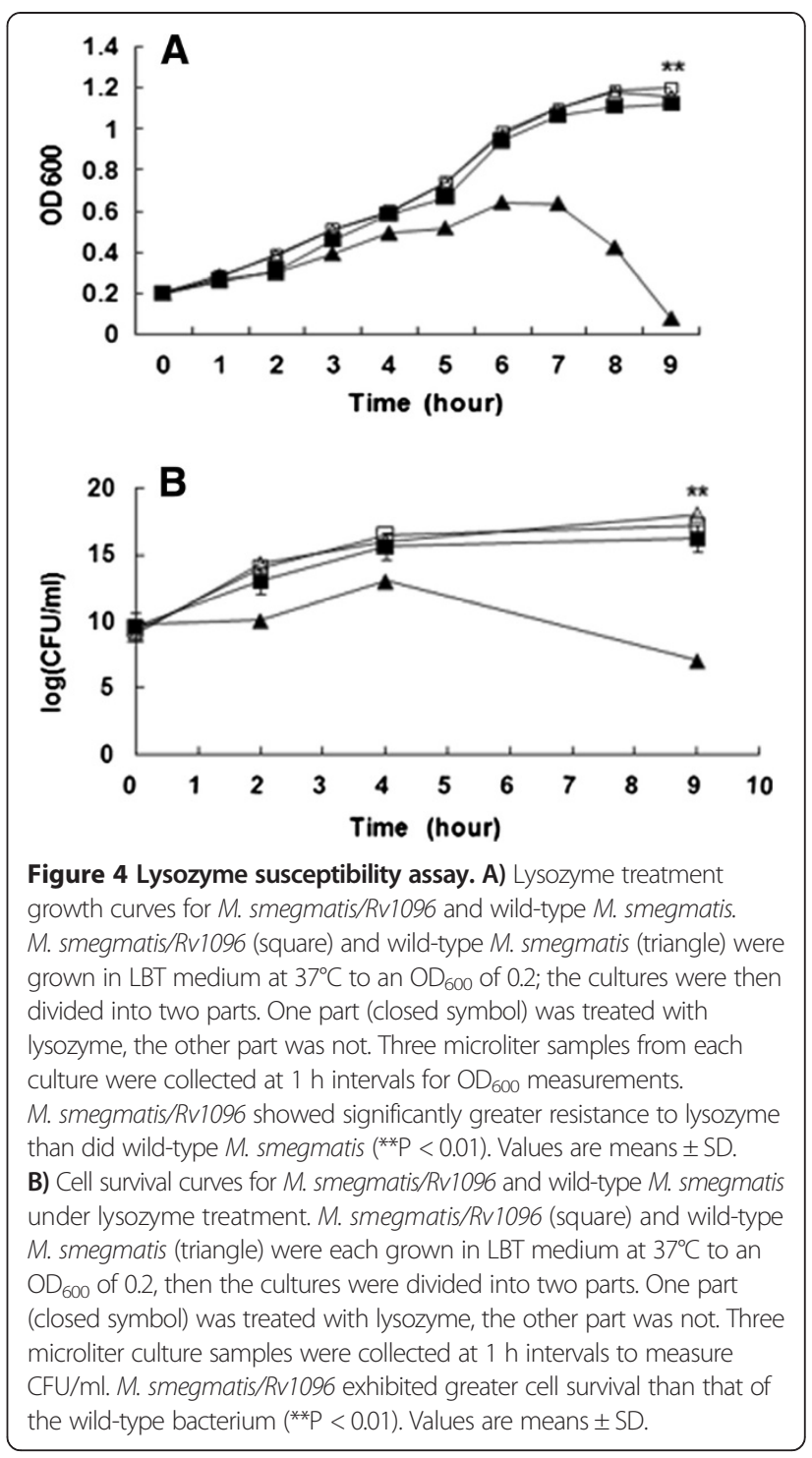

wild-type $M$. smegmatis had an irregular appearance (enlarged shape, destructed cell wall and wrinkled surface) in the presence of lysozyme, whereas M. smegmatis/Rv1096 had a regular shape, undamaged cell wall and smooth surface after $9 \mathrm{~h}$ lysozyme treatment (Figure 6).

\section{Discussion}

M. tuberculosis Rv1096 protein, S. pneumoniae PgdA protein (spPdgA), L. monocytogenes PgdA (lmo0415), and L. lactis PgdA (XynD) are carbohydrate esterase 4 (CE-4) superfamily members. The CE-4 superfamily includes peptidoglycan GlcNAc deacetylases, rhizobial NodB chito-oligosaccharide deacetylases, chitin deacetylases, acetyl xylan esterases, and xylanases [27]. The substrates of these enzymes are polymers or basic structures that assemble PG backbone glycan strands. In this study, Rv1096 protein, over-expressed in both E. coli 


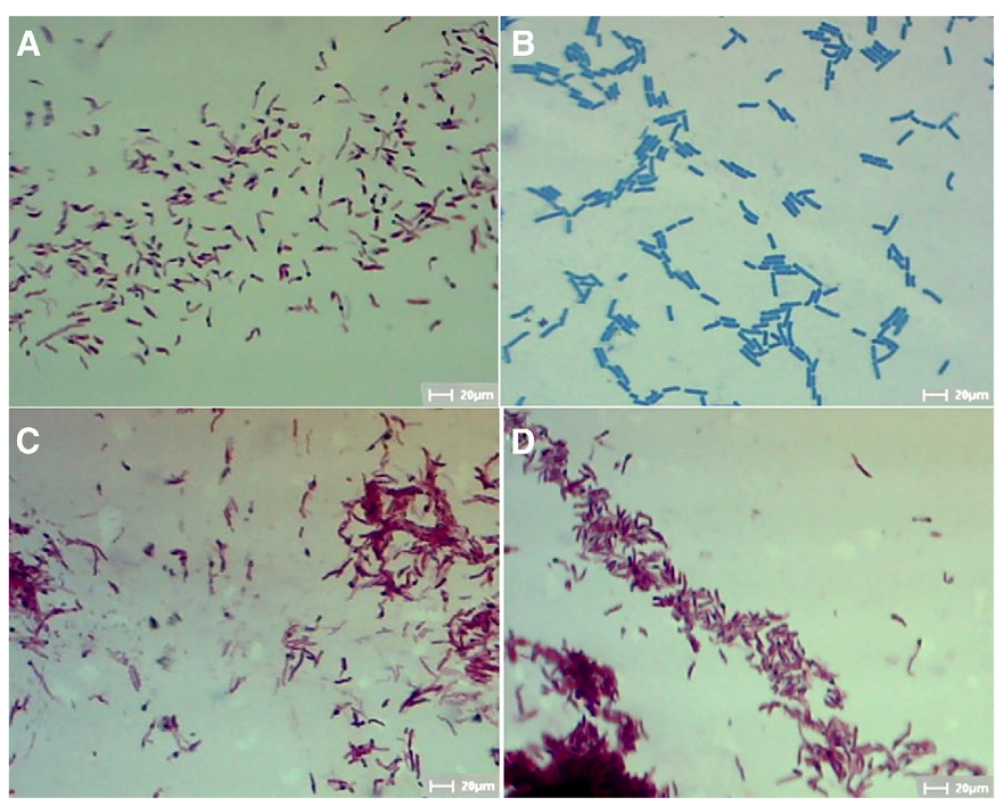

Figure 5 Acid-fast staining of $M$. smegmatis/Rv1096 and wild-type cells. A) Wild-type M. smegmatis without lysozyme treatment, B) wild-type M. smegmatis with lysozyme treatment, C) M. smegmatis/Rv1096 without lysozyme treatment and, D) M. smegmatis/Rv1096 with lysozyme treatment $(\times 1000)$. Lysozyme treatment was for $9 \mathrm{~h}$.

and M. smegmatis, was able to deacetylate M. smegmatis peptidoglycan. Therefore, M. tuberculosis Rv1096 protein is a peptidoglycan deacetylase.

As shown in Figure 1, Rv1096 and three other deacetylases share sequence conservation at two catalytic histidine residues (H-326 and $\mathrm{H}-330)$ [10]. The metal ligand sites, including Asp (D-275), Arg (A-295), Asp (D-391) and His (H-417) residues, which were identified in the S. pneumonia PgdA protein $[5,10,28]$, are all present in the Rv1096 protein. These highly conserved sequences in Rv1096

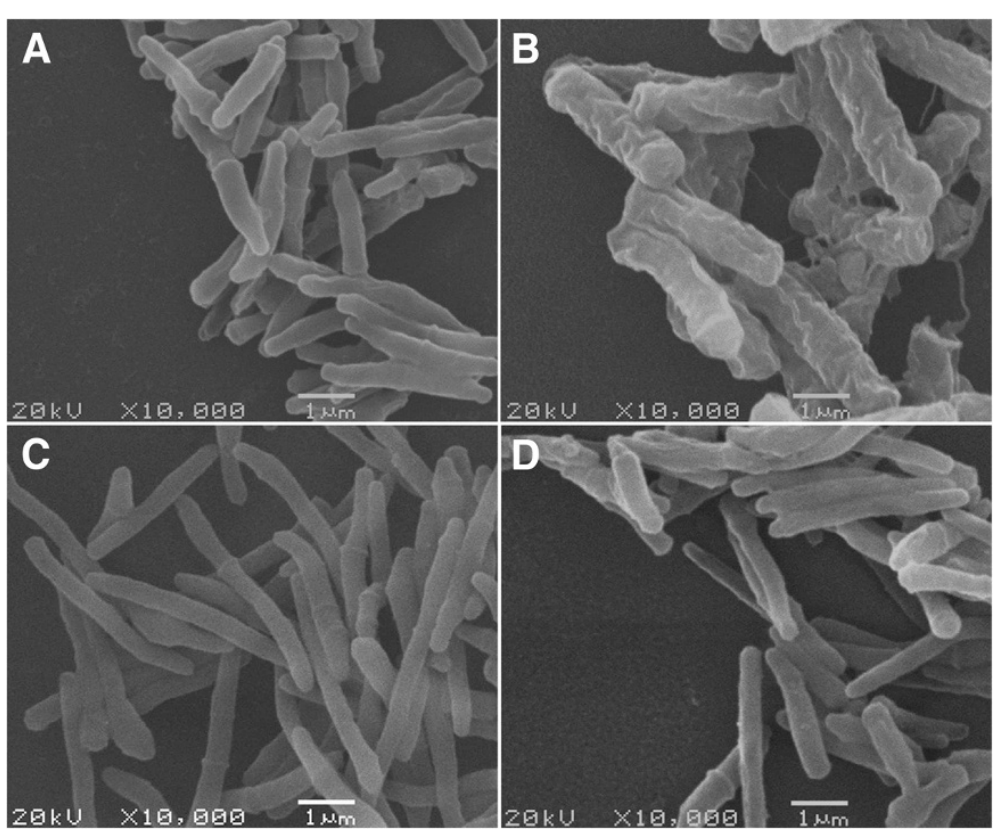

Figure 6 Scanning electron micrographs of M. smegmatis/Rv1096 and wild-type M. smegmatis. A) Wild-type M. smegmatis without lysozyme treatment, B) wild-type M. smegmatis with lysozyme treatment, C) M. smegmatis/Rv1096 without lysozyme treatment and, D) M. smegmatis/Rv1096 with lysozyme treatment. Lysozyme treatment was for $9 \mathrm{~h}$. 
suggest that it may have metallo-dependence. Indeed, our results show that the enzymatic activity of Rv1096 increased after supplementation with divalent cations, especially $\mathrm{Co}^{2+}$. Taken together, our results suggest that Rv1096 may use similar catalytic mechanisms as the $S$. pneumoniae PgdA protein to deacetylate PG.

It has been reported that PG deacetylase contributes to lysozyme resistance in some bacterial species, such as Bacillus cereus [29], S. pneumonia [10] , L. monocytogenes [6] and Shigella flexneri [28]. Generally, pdgA mutants are more sensitive to lysozyme degradation in the stationary phase. Similarly, M. smegmatis over-expressing Rv1096 protein showed remarkable resistance to lysozyme at the end of log phase growth. In the present study, the viability of M. smegmatis/Rv1096 was $10^{9}$-fold higher than that of wild-type $M$. smegmatis after lysozyme treatment, indicating that PG deacetylation by the Rv1096 deacetylase had increased lysozyme resistance. The morphological changes observed between wild-type $M$. smegmatis and M. smegmatis/Rv1096 provides strong evidence that Rv1096 activity helped to preserve the integrity of the cell wall during lysozyme treatment. Wild-type $M$. smegmatis lost its acid-fastness because of the increased cell wall permeability caused by lysozyme treatment. SEM observations showed that wild-type $M$. smegmatis had a wrinkled cell surface with outward spilling of its cell contents, while M. smegmatis/Rv1096 maintained its cell wall integrity and acid fastness. Therefore, it is likely that the functionality of the Rv1096 protein of M. smegmatis/Rv1096 contributed to its cell wall integrity.

In fact, PG N-deacetylase has been shown to be a virulence factor in several bacteria including S. pneumonia [5], S. iniae [30], L. monocytogenes [12] and H. pylori [7]. For example, the $S$. pneumoniae pdgA mutant (with a nonfunctional pdgA gene) developed hypersensitivity to exogenous lysozyme and decreased virulence in a mouse infection model [5]. Furthermore, L. monocytogenes lacking pdgA (lmo0415) was susceptible to macrophage clearance [12]. In further studies, we aim to establish whether the Rv1096 protein is a virulence factor.

\section{Conclusion}

We identified M. tuberculosis Rv1096 as a PG deacetylase and found that the PG deacetylase activity of this protein contributed to lysozyme resistance in M. smegmatis. Our findings suggest that PG deacetylation may be involved in immune evasion by $M$. tuberculosis in its host.

\footnotetext{
Abbreviations

PG: Peptidoglycan; mAGP: Mycolyl-arabinogalactan-peptidoglycan; Nod: Nucleotide-binding oligomerization domain; IPTG: Isopropyl-Dthiogalactopyranoside; PMSF: Phenylmethyl-sulphonyl fluoride; BCIP/NBT: 5-Bromo-4-chloro-3-indolyl phosphate/Nitro blue tetrazolium; SDS: Sodium dodecyl sulfate; CFU: Colony forming unit; OsO4: Omium tetroxide; SEM: Scanning electronic microscopy; CE-4: Carbohydrate esterase 4.
}

\section{Competing interests}

The authors declare that they have no competing interests.

\section{Authors' contributions}

SY constructed expression vectors, prepared Rv1096 protein and conducted lysozyme susceptibility assays, deacetylase activity assays, as well as prepared this manuscript. FZ purified Rv1096 protein and determined kinetic parameters of PG deacetylase. JK performed bioinformatic analyses of Rv1096 with known PG deacetylases. WZ performed bioinformatic analysis of Rv1096 and the statistical analyses. GD prepared samples for acid-fast staining and SEM. YX participated in designing experiments of the study. YM proposed this project, designed most of experiments and prepared this manuscript. All authors read and approved the final manuscript.

\section{Authors' information}

Shufeng Yang (M.S.) and Guoying Deng (M.S.):Department of Microbiology, Dalian Medical University Dalian 116044, China; Fei Zhang (B.S.), Jian Kang (Ph.D.), Wenli Zhang (Ph.D.) and Yufang Ma (Ph.D.): Department of Biochemistry and Molecular Biology, Dalian Medical University Dalian 116044, China. Yi Xin (Ph.D.), Department of Biotechnology, Dalian Medical University Dalian 116044, China.

\section{Acknowledgements}

This work was supported by the National Basic Research Program of China (No. 2012CB518803) and Research Fund for the Doctoral Program of Higher Education of China (No. 20112105110002).

\section{Author details}

${ }^{1}$ Department of Biochemistry and Molecular Biology, Dalian Medical University, 9 W Lushun South Road, Dalian 116044, China. Department of Microbiology, Dalian Medical University, Dalian 116044, China. ${ }^{3}$ Department of Biotechnology, Dalian Medical University, Dalian 116044, China. ${ }^{4}$ Liaoning Provincial Core Lab of Glycobiology and Glycoengineering, Dalian 116044, China.

Received: 17 January 2014 Accepted: 25 June 2014

Published: 30 June 2014

\section{References}

1. Watts G: WHO annual report finds world at a crossroad on tuberculosis. BMJ 2012, 345:e7051-e7061.

2. Behar SM, Divangahi M, Remold HG: Evasion of innate immunity by Mycobacterium tuberculosis: is death an exit strategy? Nat Rev Microbiol 2010, 8(9):668-674.

3. Boneca IG: The role of peptidoglycan in pathogenesis. Curr Opin Microbiol 2005, 8(1):46-53.

4. Girardin SE, Travassos LH, Herve M, Blanot D, Boneca IG, Philpott DJ, Sansonetti PJ, Mengin-Lecreulx D: Peptidoglycan molecular requirements allowing detection by Nod1 and Nod2. J Biol Chem 2003, 278(43):41702-41708.

5. Vollmer W, Tomasz A: Peptidoglycan N-acetylglucosamine deacetylase, a putative virulence factor in Streptococcus pneumoniae. Infect Immun 2002, 70(12):7176-7178.

6. Lenz LL, Mohammadi S, Geissler A, Portnoy DA: SecA2-dependent secretion of autolytic enzymes promotes Listeria monocytogenes pathogenesis. Proc Natl Acad Sci U S A 2003, 100(21):12432-12437.

7. Wang G, Maier SE, Lo LF, Maier G, Dosi S, Maier RJ: Peptidoglycan deacetylation in Helicobacter pylori contributes to bacterial survival by mitigating host immune responses. Infect Immun 2010, 78(11):4660-4666.

8. Vollmer W, Tomasz A: The pgdA gene encodes for a peptidoglycan Nacetylglucosamine deacetylase in Streptococcus pneumoniae. J Biol Chem 2000, 275(27):20496-20501.

9. Inês Crisóstomo M, Vollmer W, AS K O, Gehre F, Buckenmaier S, Tomasz A: Attenuation of penicillin resistance in a peptidoglycan O-acetyl transferase mutant of Streptococcus pneumoniae. Molecular Microbiol 2006, 61(6):1497-1509.

10. Blair DE, Schuttelkopf AW, MacRae JI, van Aalten DM: Structure and metaldependent mechanism of peptidoglycan deacetylase, a streptococcal virulence factor. Proc Natl Acad Sci U S A 2005, 102(43):15429-15434.

11. Popowska M, Osińska M, Rzeczkowska M: N-acetylglucosamine-6phosphate deacetylase (NagA) of Listeria monocytogenes EGD, an 
essential enzyme for the metabolism and recycling of amino sugars. Arch Microbiol 2011, 194(4):255-268.

12. Boneca IG, Dussurget $O$, Cabanes D, Nahori MA, Sousa S, Lecuit M, Psylinakis E, Bouriotis V, Hugot JP, Giovannini M, Coyle A, Bertin J, Namane A, Rousselle JC, Cayet N, MC P' V, Balloy V, Chignard M, Philpott DJ, Cossart P, Girardin SE: A critical role for peptidoglycan $\mathrm{N}$-deacetylation in Listeria evasion from the host innate immune system. Proc Natl Acad Sci U S A 2007, 104(3):997-1002.

13. Meyrand M, Boughammoura A, Courtin P, Mezange C, Guillot A, ChapotChartier MP: Peptidoglycan $\mathrm{N}$-acetylglucosamine deacetylation decreases autolysis in Lactococcus lactis. Microbiology 2007, 153(Pt 10):3275-3285.

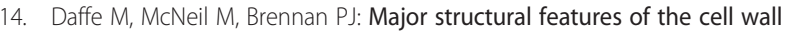
arabinogalactans of Mycobacterium, Rhodococcus, and Nocardia spp. Carbohydr Res 1993, 249(2):383-398.

15. Chen WP, Kuo TT: A simple and rapid method for the preparation of gram-negative bacterial genomic DNA. Nucleic Acids Res 1993, 21(9):2260

16. Fukushima T, Kitajima T, Sekiguchi J: A polysaccharide deacetylase homologue, PdaA, in Bacillus subtilis acts as an $\mathrm{N}$-acetylmuramic acid deacetylase in vitro. J Bacteriol 2005, 187(4):1287-1292.

17. Mahapatra S, Scherman H, Brennan PJ, Crick DC: N Glycolylation of the nucleotide precursors of peptidoglycan biosynthesis of Mycobacterium spp. is altered by drug treatment. J Bacteriol 2005, 187(7):2341-2347.

18. Mahapatra S, Crick DC, McNeil MR, Brennan PJ: Unique structural features of the peptidoglycan of Mycobacterium leprae. J Bacteriol 2008, 190(2):655-661.

19. He Z, De Buck J: Cell wall proteome analysis of Mycobacterium smegmatis strain MC2 155. BMC Microbiol 2010, 10:121.

20. Kobayashi K, Sudiarta IP, Kodama T, Fukushima T, Ara K, Ozaki K, Sekiguchi J: Identification and characterization of a novel polysaccharide deacetylase C (PdaC) from Bacillus subtilis. J Biol Chem 2012, 287(13):9765-9776.

21. Mahapatra S, Crick DC, Brennan PJ: Comparison of the UDP-Nacetylmuramate:L-alanine ligase enzymes from Mycobacterium tuberculosis and Mycobacterium leprae. J Bacteriol 2000, 182(23):6827-6830

22. Raymond JB, Mahapatra S, Crick DC, Pavelka MS Jr: Identification of the namH gene, encoding the hydroxylase responsible for the $\mathrm{N}$-glycolylation of the mycobacterial peptidoglycan. J Biol Chem 2005, 280(1):326-333.

23. Kang J, Xu L, Yang S, Yu W, Liu S, Xin Y, Ma Y: Effect of phosphoglucosamine mutase on biofilm formation and antimicrobial susceptibilities in M. smegmatis glmM gene knockdown strain. PLoS One 2013, 8(4):e61589.

24. Tafelmeyer P, Laurent C, Lenormand P, Rousselle JC, Marsollier L, Reysset G, Zhang R, Sickmann A, Stinear TP, Namane A, Cole S: Comprehensive proteome analysis of Mycobacterium ulcerans and quantitative comparison of mycolactone biosynthesis. Proteomics 2008, 8(15):3124-3138.

25. Blair DE, van Aalten DM: Structures of Bacillus subtilis PdaA, a family 4 carbohydrate esterase, and a complex with $\mathrm{N}$-acetyl-glucosamine. FEBS Lett 2004, 570(1-3):13-19.

26. Bui NK, Turk S, Buckenmaier S, Stevenson-Jones F, Zeuch B, Gobec S, Vollmer W: Development of screening assays and discovery of initial inhibitors of pneumococcal peptidoglycan deacetylase PgdA. Biochem Pharmacol 2011, 82(1):43-52.

27. Leal AF, de Lima Neto RG, Macedo DP, Beltrao El, Neves RP: Carbohydrate profiling of fungal cell wall surface glycoconjugates of Trichophyton tonsurans and other keratinophilic filamentous fungi using lectins. Mycoses 2011, 54(6):e789-e794.

28. Kaoukab-Raji A, Biskri L, Bernardini ML, Allaoui A: Characterization of SfPgdA, a Shigella flexneri peptidoglycan deacetylase required for bacterial persistence within polymorphonuclear neutrophils. Microbes Infect 2012, 14(7-8):619-627.

29. Psylinakis E, Boneca IG, Mavromatis K, Deli A, Hayhurst E, Foster SJ, Varum KM, Bouriotis V: Peptidoglycan N-acetylglucosamine deacetylases from Bacillus cereus, highly conserved proteins in Bacillus anthracis. J Biol Chem 2005, 280(35):30856-30863.

30. Milani CJ, Aziz RK, Locke JB, Dahesh S, Nizet V, Buchanan JT: The novel polysaccharide deacetylase homologue Pdi contributes to virulence of the aquatic pathogen Streptococcus iniae. Microbiology 2010, 156(Pt 2):543-554.

doi:10.1186/1471-2180-14-174

Cite this article as: Yang et al:: Mycobacterium tuberculosis Rv1096 protein: gene cloning, protein expression, and peptidoglycan deacetylase activity. BMC Microbiology 2014 14:174.

\section{Submit your next manuscript to BioMed Central and take full advantage of:}

- Convenient online submission

- Thorough peer review

- No space constraints or color figure charges

- Immediate publication on acceptance

- Inclusion in PubMed, CAS, Scopus and Google Scholar

- Research which is freely available for redistribution 